\section{New Thematic and Methodological Research Focus in the Social Sciences and the Humanities: The BRICS Countries Grouping}

\section{Dr Charl Wolhuter ${ }^{+*}$ and Dr Oxana Chigisheva ${ }^{*}$}

The world of the early 21st Century is a rapidly changing world, looking much different from the world as little as forty years ago. One of the signature features of this new world is the Global South, or more broadly, the extra-Western world coming of age and becoming a factor in the global power equation. This changing global demography and economy, and its translation into political power, have wide-ranging consequences, including scholarship. Among the nations in the extra-Western world, the BRICS (Brazil, Russia, India, China, South Africa) formation has naturally assumed a vanguard position because of its geographic, demographic and economic weight. These countries are pressed to make serious efforts for progress in education, science and real-life impact research in order to accelerate the transition to a new technological stage and not to be left behind the rest of the world. As natural sciences are developing more dynamically, the social sciences and humanities are a different matter, requiring discussion and special concern. Thus, this Special Issue focuses on the contribution of the BRICS countries into epistemological development and innovation in the social sciences and humanities.

In the lead article, the two guest editors outline this rise of the BRICS countries to prominence on the world stage and as the vanguard of the collection of nations of the Global South, and the significance of this development for epistemological developments in the Humanities and Social Sciences. All BRICS countries, as countries in the Global South in

\footnotetext{
${ }^{\dagger}$ Professor, Comparative and International Education, North-West University, Potchefstroom Campus, South Africa, Email: Charl.Wolhuter@nwu.ac.za

(C) 2020 Wolhuter \& Chigisheva. This is an Open Access article distributed under the terms of the Creative Commons Attribution License (http://creativecommons.org/licenses/by/2.0), which permits unrestricted use, distribution, and reproduction in any medium, provided the original work is properly cited.

${ }^{*}$ Associate Professor, Southern Federal University, Rostov-on-Don, Russia, Email: opchigisheva@sfedu.ru
}

general, have acutely multicultural population compositions.

In her article, Professor Emeritus Ana Avenicki explains how research on multiculturalism in the BRICS countries can contribute to the global corpus of Humanities and Social Studies.

The article by Professor Ewelina Kinga Niemczyk focuses on the improvement of research capacity in the BRICS countries. Two powerful ways for BRICS countries to enhance their profile in the global world of scholarship would befirst, to use their institutions of higher education and increase collaboration of these institutions of higher education with each other and second, to put comparative studies comparing the BRICS countries with each other, on the research agenda.

In his article, Oscar Eybers demonstrates the value of research based on social realist ontology, also a means of research for conducting comparative studies of systems of higher education in the BRICS countries.

The article by Anastasia A. Atabekova, Rimma G. Gorbatenko, Tatyana V. Shoustikova provides original and interesting data on the conceptual vision and perception of the phenomenon of BRICS in the modern world by various stakeholders. This complex multimodal discourse is analysed from the linguistic perspective and demonstrates how it may be used to shape the needed perception of BRICS at the international arena.

Ekaterina V. Zvereva, Nataliya M. Belenkova, Irina I. Kruse analyse higher education environment of the BRICS educational institutions, reveal and compare some peculiarities of professional training in these countries and represent the experience of RUDN University being a part of the BRICS Net University. The achievements of RUDN look 
promising and may be easily multiplied for achieving higher education harmonisation in the BRICS countries.

Svetlana V. Ivanova and Oleg B. Ivanov's article states the very acute and timely issues faced by the Russian education system, which is due to global technological and industrial shifts. The authors prove that these challenges are easy to deal within a single global educational space based on the humanistic needs of the society. They evaluate its potential benefits for the BRICS countries (precisely Russia) within the challenges of the progress and global race for leadership.

The complexities of today's educational agenda are also debated in the article by Natalia E. Sudakova and Olga N. Astafyeva, who examines inclusion as a modern culture phenomenon and universal mechanisms of its formation. Inclusion policies in the sphere of culture and education, as well as existing inclusive initiatives, are evaluated in the research from the point of their importance for the development of humanistic thinking in the BRICS countries.

In the concluding paper, the guest-editors consider the necessity for researching educational issues in the very diverse (culturally, economically, historically) BRICS countries from one methodological basis. The authors offer the model which suits this purpose and allow a three-dimensional analysis (quantitative, qualitative, equality) of the studied national educational phenomena. This model may also be methodologically relevant in case of researching societal outcomes of education. It is clear that comparativists should significantly reinforce their positions in social sciences and humanities research produced in the BRICS countries.

We believe that this special issue provides a critical and fuller picture of the existing research trends, thematic diversity, methodological tools and tactics choices that dominate in modern social sciences and humanities (education, psychology, sociology, linguistics, the economics of education etc.) research projects. We also hope that the authors managed to highlight a mosaic of present and future research foci in the BRICS countries and establish their correlation with the existing global trends in the fields. Thus, perhaps laying the cornerstone for further development of inter-BRICS countriesComparative Education research. 